\title{
The dynamics of welfare entry and exit amongst natives and immigrants
}

\author{
By Christoph Wunder* and Regina T. Riphahn ${ }^{\dagger}$
}

${ }^{\star}$ Department of Economics, University of Erlangen-Nuremberg, Lange Gasse 20, 90403 Nuremberg, Germany; e-mail: christoph.wunder@fau.de $\uparrow$ University of Erlangen-Nuremberg

This article studies welfare entry and exit in Germany and determines the relevance of state dependence for natives and immigrants. Based on dynamic multinomial logit estimations, we calculate transition matrices between three labour market states. We find that temporal persistence in welfare participation can mostly be explained by observed and unobserved characteristics. Immigrants appear to have a higher risk of welfare entry and a lower probability of welfare exit compared to natives. The results do not yield strong evidence of state dependence or of an overall welfare trap.

JEL classifications: I38, J61.

\section{Introduction}

Persistence in welfare participation is a common observation. Recipients receive welfare benefits often for prolonged and repeated periods (e.g., Moffitt, 1992; Blank and Ruggles, 1994; Green and Warburton, 2004). Persistence can be explained by two distinct mechanisms. One is that past welfare receipt directly affects individual preferences or constraints and thereby determines subsequent welfare exit and entry behaviour. This mechanism, referred to as true (or structural) state dependence (Heckman, 1981a), may generate a welfare trap (Plant, 1984). Another mechanism is spurious state dependence that arises if the correlation in welfare receipt over time results from observed or unobserved individual-specific heterogeneity.

Information about state dependence may help identify weaknesses in the welfare system. In particular, state dependence might drive immigrant-native differences in the incidence of welfare receipt (for a survey, see Barrett and McCarthy, 2008). If immigrants and natives differ in their true state dependence, the welfare system could be reformed to address such group-specific behavioural responses. As an example, the evidence for true state dependence in the US federal welfare system motivated reforms in the mid-1990s (Sandefur and Cook, 1997). Because welfare participation was relatively high amongst immigrants, the reforms excluded new immigrants from most means-tested benefits (Kaestner and Kaushal, 2005). 
If, on the other hand, immigrant-native differences are due to heterogeneity, group-specific programmes that directly address the determinants of welfare receipt (e.g., training programmes to improve the human capital of immigrants) are likely to be more effective.

This study explores to what extent the observed persistence in welfare participation can be attributed to true state dependence and which part can be explained by heterogeneity. We also investigate whether immigrant-native differences in the dynamics of welfare receipt can be explained by differences in characteristics. The analysis is presented separately for natives and various immigrant subsamples in Germany after 2005, when the welfare system was reformed. We focus on unemployment benefit II, the means-tested tax-financed welfare benefit paid to persons who are capable of work.

We apply dynamic multinomial logit models with controls for observed and unobserved heterogeneity and endogenous initial conditions to identify true state dependence and the existence of a welfare trap. The models consider transitions between employment, inactivity, and welfare receipt. The findings suggest that the temporal persistence in welfare participation can be largely explained by observed and unobserved characteristics. Immigrants have a higher risk of welfare entry and a lower probability of welfare exit than natives. Amongst all immigrants, non-EU citizens are identified as a group with particular problems: they have the lowest employment stability, the highest persistence in welfare participation, the highest welfare entry, and the lowest welfare exit rates. Immigrant-native differences in welfare dynamics narrow when differences in characteristics are taken into account. However, for non-EU citizens a substantial unexplained immigrantnative gap remains. Overall, there is little evidence for a general welfare trap.

Although various contributions have studied immigrant-native differences in welfare participation, few authors applied dynamic estimation approaches to distinguish true from spurious state dependence. Hansen and Lofstrom (2009) study the transition between welfare receipt, unemployment, and employment in Sweden between 1990 and 1996. They find that true state dependence is higher amongst immigrants than natives and confirm the existence of a welfare trap for immigrants. In a later analysis (Hansen and Lofstrom, 2011), the authors find that the difference in welfare receipt between natives and immigrants results from differences in entry to rather than exit from welfare.

Bratsberg et al. (2010) study immigrant employment in Norway. Compared to natives, immigrants have substantially higher exit rates from employment and significantly higher state dependence in nonemployment. Important determinants are household characteristics, immigrants' selection into weak industries, the sensitivity of their jobs to the business cycle, and weak work incentives of the welfare system. Similarly, Farrell and Frijters (2008) suggest that the welfare system may remove incentives for human capital investments early in life, affecting subsequent labour market opportunities.

There are additional contributions on the state dependence of welfare receipt that do not focus on the immigrant-native welfare gap. Hansen et al. (2006) study 
Canadian welfare participation and find substantial true state dependence, particularly in regions with high benefit levels. Using Californian data, Chay et al. (2004) provide evidence for first- and second-order state dependence in welfare receipt and show that the magnitude of state dependence varies across population groups. Cappellari and Jenkins (2009) study welfare receipt in Britain and find little evidence for state dependence. The authors argue that the decline in British welfare participation was driven by falling entry rates, which are correlated with unemployment and reforms of the welfare system.

The German literature on welfare participation is limited. One group of contributions studies take-up behaviour. ${ }^{1}$ Transitions in and out of welfare receipt have been analysed based on cross-sectional data by Wilde (2003), Aldashev and Fitzenberger (2009) and Schels (2011). Riphahn (2004) compared native and immigrant welfare receipt between 1984 and 1996. So far, no contribution considers state dependence and transition dynamics.

Except for Hansen and Lofstrom $(2009,2011)$ the difference in welfare dynamics for natives and immigrants has remained largely unexplored in the literature. As a result, we do not know whether immigrant state dependence in welfare receipt is common or merely a Swedish phenomenon, and whether there is heterogeneity in state dependence across immigrants from different origins and with or without host country citizenship. We contribute to the literature by answering these questions. In addition, we are the first to study welfare exit and entry in a dynamic framework in Germany after the welfare reform of 2005, to provide evidence on whether welfare traps are pervasive, and whether these mechanisms differ across population groups.

\section{Institutions}

The German income support system was reformed between 2002 and 2005. The important reform elements include (i) the combination of two pre-reform benefit programmes (unemployment assistance and social assistance) into one post-reform programmes (unemployment benefit II), (ii) enforcement of active job search with the threat of substantial sanctions, and (iii) enhanced of work incentives, for example, through higher earnings allowances and lower marginal tax rates (for a summary, see, e.g., Caliendo 2009; Riphahn and Wunder, 2012). This section briefly describes post-reform minimum income protection for natives and immigrants. The two institutions relevant to our analyses are the unemployment insurance (UI) and the welfare system.

Unemployed individuals are eligible for UI benefits conditional on prior insurance contributions and active job search. UI benefits replace up to $67 \%$ of prior net labour earnings. The benefits are typically provided for up to 12 months

\footnotetext{
${ }^{1}$ Differences in take-up behaviour between natives and immigrants could affect the interpretation of our results. However, the literature generally does not find significant differences for the subsamples, see, for example, Riphahn (2001), Wilde and Kubis (2005), or Bruckmeier and Wiemers (2012).
} 
and slightly longer for older unemployeds. UI benefits are labelled unemployment benefits I (UB I). They are not means-tested and are identically available for immigrants and natives, independent of citizenship.

The objective of the German welfare system is to ensure that all legal residents can lead a dignified life based on an administratively set minimum income. This minimum income is calculated for a given household based on the number and age of household members. It is provided as a benefit and independent of past earnings to those in need. Since the 2005 reform, the German welfare system distinguishes between those who are able to work and those who are not. Those able to work but with insufficient income can claim means-tested unemployment benefits II (UB II), that is, welfare benefits from the tax-financed welfare system. ${ }^{2}$ UB II are available for both, the unemployed without (sufficient) claims to the unemployment insurance (including recipients of UB I) and those who are employed but whose earnings do not meet their needs. Eligibility requirements for UB II receipt are (i) a means-tested need, (ii) the ability to work at least 15 hours per week, (iii) being between age 15 and 65, and (iv) having permanent residence rights in Germany, which excludes tourists, seasonal workers, and asylum seekers. Individuals living with a welfare recipient receive welfare if they are a dependent child, partner, or parent in the same household (see BMAS, 2010). Since the 2005 welfare reform, work incentives have been strengthened, welfare recipients are activated and enabled to re-enter the labour market, and a stricter sanctioning regime has been implemented.

In contrast to the unemployment insurance, the welfare system distinguishes based on citizenship: ${ }^{3}$ generally, individuals without German citizenship can claim UB II beginning with their fourth month of stay in Germany if they are allowed to take up employment, which again depends on their immigrant status: asylum seekers, for example, are not eligible for welfare and receive separate asylum seeker benefits. Non-German immigrants residing in Germany to find employment are not eligible. However, a long list of circumstances renders EU citizens (and those treated like them) eligible for UB II receipt (see Classen, 2009). Generally, those immigrants who are not eligible for UB II are likely to be eligible for benefits from the social assistance scheme. In some situations, the prolongation of the right to stay or an improvement in immigrant status can be refused if an immigrant is in need of public means-tested support. Here, the receipt of UB I is not relevant, as it is not means-tested. Special protection is granted to migrants from signatory states of the European Convention on Social and Medical Assistance of 1953, which covers immigrants from EU member states, Iceland, Norway, and-importantly-Turkey. Immigrants from these states generally cannot lose

\footnotetext{
${ }^{2}$ Those who are not healthy enough or too old to work receive minimum income transfers from the social assistance programme (Soziahilfe) or income support for the elderly (Grundsicherung).

${ }^{3}$ Ethnic Germans, that is, Germans who moved to Eastern Europe before World War II, receive German citizenship immediately when entering Germany. They and other naturalized immigrants are treated like natives.
} 
their right to stay in Germany as a consequence of welfare receipt (see Classen, 2009). In addition, the receipt of UB II can preclude naturalization if welfare receipt is a consequence of individual behaviour.

Overall, welfare receipt and welfare transitions may differ between native and immigrant households for a number of reasons. First, immigrants may have different incomes and family sizes, which affects welfare eligibility and may have consequences for welfare transitions. Second, the groups may differ with respect to preferences and opportunities. For example, selective migration to Germany as a 'welfare magnet' (Borjas, 1999) may in principle explain a native-immigrant gap in welfare dependence and render differences in state dependence plausible. Also, discrimination may lead to different labour market opportunities. Third, benefit take-up behaviour may differ for the groups due to either differences in perceived stigma or heterogeneous information costs. Information deficits also may render one group less responsive to employment incentives than the other. Finally, differences in the distribution of wealth between native and immigrant households may affect both the transition to welfare in case of income loss and the persistence in welfare receipt over time.

\section{Data}

The data used in this article are taken from the Socio-Economic Panel Study (SOEP) that provides longitudinal information about natives and immigrants in Germany (see Wagner et al., 2007). Our data cover the period 2005-2009 and include individuals conditional on being in the sample in 2005, which is our initial state. We study working-age adults (aged 25-65) and exclude disabled persons because UB II is only granted to individuals with full earning capacity. The sample is restricted to West Germany because the proportion of immigrant households in East Germany is negligible (for similar sample selection criteria, see Kogan, 2004 and Riphahn, 2004).

We use a migration background indicator to delineate our immigrant sample, which combines first- and second-generation immigrants independent of citizenship. We distinguish three immigrant groups: EU citizens (excluding Germans), non-EU citizens, and immigrants with German citizenship. ${ }^{4}$ Descriptive statistics for our subsamples are presented in Table $1 .{ }^{5}$ Obvious immigrant-native differences

\footnotetext{
${ }^{4}$ Individuals with EU citizenship are defined as citizens of EU member states (excluding Germany) and citizens of states that are treated as legally equivalent. The corresponding states are Austria, Belgium, Bulgaria, Czech Republic, Denmark, Finland, France, Great Britain, Greece, Holland, Hungary, Ireland, Italy, Latvia, Lithuania, Luxembourg, Norway, Poland, Portugal, Romania, Slovakia, Slovenia, Spain, Sweden, Switzerland. Persons of Italian or Greek nationality dominate this group with a share of $38 \%$ and 22\%, followed by Spaniards (9\%). All other nationalities are regarded as immigrants with non-EU citizenship. They are predominantly from Turkey (58\%) and the successor states of the former Yugoslavia (29\%). Immigrants with German citizenship are primarily second-generation immigrants and ethnic Germans.

${ }^{5}$ Further descriptive statistics by labour market state are provided in Tables A3-A5 in the online Appendix.
} 
Table 1 Descriptive statistics

\begin{tabular}{|c|c|c|c|c|c|c|c|c|c|c|}
\hline \multirow[b]{2}{*}{ Variable } & \multicolumn{2}{|l|}{$\begin{array}{l}\text { Natives } \\
\ldots \ldots \ldots \ldots . . . . .\end{array}$} & \multicolumn{2}{|c|}{$\begin{array}{l}\text { All } \\
\text { immigrants } \\
\ldots \ldots \ldots \ldots \ldots \ldots \ldots . . . . . . . . . .\end{array}$} & \multicolumn{2}{|l|}{$\begin{array}{l}\text { EU } \\
\text { citizens } \\
\ldots \ldots \ldots \ldots . . . .\end{array}$} & \multicolumn{2}{|c|}{$\begin{array}{l}\text { Non-EU } \\
\text { citizens } \\
\text {.............. }\end{array}$} & \multicolumn{2}{|c|}{$\begin{array}{l}\text { Immigrants } \\
\text { with German } \\
\text { citizenship }\end{array}$} \\
\hline & Mean & SD & Mean & SD & Mean & SD & Mean & SD & Mean & SD \\
\hline Inactivity & 0.182 & 0.386 & 0.228 & 0.419 & 0.184 & 0.388 & 0.316 & 0.465 & 0.196 & 0.397 \\
\hline Employment & 0.792 & 0.406 & 0.698 & 0.459 & 0.763 & 0.425 & 0.582 & 0.493 & 0.736 & 0.441 \\
\hline Welfare receipt & 0.030 & 0.171 & 0.079 & 0.270 & 0.053 & 0.225 & 0.106 & 0.308 & 0.074 & 0.261 \\
\hline Age & 45.56 & 9.806 & 43.42 & 10.471 & 45.14 & 10.11 & 42.86 & 10.66 & 43.07 & 10.44 \\
\hline Female & 0.530 & 0.499 & 0.545 & 0.498 & 0.536 & 0.499 & 0.530 & 0.499 & 0.558 & 0.497 \\
\hline Education in years & 12.51 & 2.674 & 11.30 & 2.594 & 11.04 & 2.550 & 10.34 & 2.378 & 11.92 & 2.547 \\
\hline Married & 0.688 & 0.463 & 0.755 & 0.430 & 0.743 & 0.437 & 0.830 & 0.375 & 0.719 & 0.450 \\
\hline Health status: good & 0.549 & 0.498 & 0.545 & 0.498 & 0.552 & 0.498 & 0.549 & 0.498 & 0.540 & 0.498 \\
\hline School in Germany: no & - & - & 0.429 & 0.495 & 0.460 & 0.499 & 0.546 & 0.498 & 0.354 & 0.478 \\
\hline Number of children LT6 & 0.157 & 0.441 & 0.228 & 0.518 & 0.165 & 0.421 & 0.237 & 0.519 & 0.247 & 0.548 \\
\hline Number of children GE6 & 0.487 & 0.810 & 0.671 & 0.920 & 0.570 & 0.774 & 0.843 & 1.023 & 0.616 & 0.900 \\
\hline Year 2007 & 0.261 & 0.439 & 0.266 & 0.442 & 0.260 & 0.439 & 0.275 & 0.447 & 0.263 & 0.441 \\
\hline Year 2008 & 0.237 & 0.426 & 0.233 & 0.423 & 0.230 & 0.421 & 0.226 & 0.419 & 0.239 & 0.426 \\
\hline Year 2009 & 0.213 & 0.409 & 0.198 & 0.398 & 0.202 & 0.402 & 0.177 & 0.382 & 0.207 & 0.405 \\
\hline \multicolumn{11}{|l|}{$\begin{array}{l}\text { Initial condition } \\
\quad \text { (in 2005) }\end{array}$} \\
\hline Inactivity & 0.185 & 0.388 & 0.262 & 0.440 & 0.217 & 0.412 & 0.347 & 0.476 & 0.233 & 0.423 \\
\hline Employment & 0.790 & 0.407 & 0.679 & 0.467 & 0.736 & 0.441 & 0.576 & 0.494 & 0.713 & 0.453 \\
\hline Welfare receipt & 0.025 & 0.155 & 0.060 & 0.237 & 0.047 & 0.212 & 0.077 & 0.267 & 0.055 & 0.227 \\
\hline $\begin{array}{l}\text { Number of person-year } \\
\text { observations }\end{array}$ & \multicolumn{2}{|c|}{20,973} & \multicolumn{2}{|c|}{5,678} & \multicolumn{2}{|c|}{1,124} & \multicolumn{2}{|c|}{1,609} & \multicolumn{2}{|c|}{2,945} \\
\hline
\end{tabular}

Source: SOEP 2005-2009.

exist with respect to education and the number of children. They are most pronounced for non-EU citizens, who have, on average, at least two years less of education and approximately twice as many children as natives.

Our dependent variable is defined as follows: first, the study of welfare transitions requires a clear-cut distinction between welfare recipients and non-recipients. This allows precise determination of welfare entry and exit and estimation of separate persistence parameters for welfare recipients and non-recipients. Therefore, we code all respondents who receive welfare benefits (i.e., UB II) as welfare recipients. ${ }^{6}$ Welfare recipients are long-term unemployed persons who exhausted their unemployment insurance benefits (UB I), employed with earnings below household needs, or UB I recipients whose unemployment benefit does not meet households needs (see Section 2).

\footnotetext{
${ }^{6}$ The information about welfare receipt is taken from a question about the respondents' personal incomes at the time of the interview. In addition, the SOEP provides information about the total number of months of welfare receipt. However, as the timing is not observed there, we only have precise information for the time of the interview. Therefore, we follow the literature and use annual state measures (see, e.g., Cappellari and Jenkins, 2004; Hansen and Lofstrom, 2009; Devicienti, 2011).
} 
In principle, we could limit our analysis to a binary indicator of welfare receipt leaving all non-recipients in the alternative group. However, we take account of the most important difference amongst non-recipients, that is, their employment status, and define two additional subgroups: one subgroup comprises individuals who are employed, including full-time and part-time employment as well as participation in vocational training. The other subgroup and our final outcome category considers 'inactive' persons, that is, those who are neither welfare recipients nor employed but instead out of the labour force or unemployed. ${ }^{7}$ Compared to a simple binary indicator, our three-state classification provides additional information about whether welfare exit is to employment or whether individuals leave the welfare programme without finding employment.

Table 1 shows important differences in the dependent variable for immigrants and natives. First, the employment rate amongst natives averages at $79 \%$ compared to $70 \%$ for all immigrants. Second, the share of immigrants receiving welfare is more than twice as large than natives'. Third, we find heterogeneity in labour market participation patterns between immigrant groups. The employment rate of immigrants with non-EU citizenship is 21 percentage points below that of natives and they are three times more likely to receive welfare benefits than natives.

Table 2 describes the observed labour market transitions. Employment is the most stable state. The probability of being employed in two successive years is similar for EU citizens (93.7\%), immigrants with German citizenship (92.7\%), and natives $(94.3 \%)$. In contrast, the employment persistence of non-EU citizens is as low as $88.2 \%$; they have the highest probability of transiting from employment to welfare. Welfare participation is persistent as approximately $75 \%$ of those who received welfare benefits in $t-1$ are also recipients in $t$. Next, we introduce a statistical model that allows us to study the extent of true state dependence.

\section{Estimation strategy}

Our dependent variable describes individuals' labour market state in period $t$, where we distinguish inactivity, employment, and welfare receipt. We model the probability of being in a particular state based on a random utility model, where the utility of individual $i$ in state $j$ at time $t$ is

$$
U_{i j t}=\beta_{j}^{\prime} \mathbf{x}_{i t}+\gamma^{\prime}{ }_{j} \mathbf{y}_{i, t-1}+\alpha_{i j}+\epsilon_{i j t} .
$$

The nonstochastic part of eq. 1 consists of a linear function of socioeconomic characteristics, $\mathbf{x}_{i t}$, which can vary over individuals and time. $\beta_{j}$ is a vector of

\footnotetext{
${ }^{7}$ Individuals in the inactive group neither work nor rely on tax-financed welfare benefits. Overall, $15 \%$ of all inactive individuals are unemployed. For additional details see Table A2 in the online Appendix. Whereas in principle the 'inactive' group could be split into the unemployed and the non-employed, we decided against this option because it resulted in groups with very few observations, especially for the immigrant subsamples. This does not allow for reliable estimations of the transition matrices. The definition of the inactive group rules out that unemployed individuals who are welfare recipients are treated as inactive. They are in the welfare category.
} 
Table 2 Observed probabilities of labour market transitions by immigrant group

\begin{tabular}{|c|c|c|c|}
\hline \multirow[t]{2}{*}{ State in $t-1$} & \multicolumn{3}{|c|}{ State at time $t$} \\
\hline & Inactivity & Employment & Welfare \\
\hline \multicolumn{4}{|l|}{ A. Natives } \\
\hline Inactivity & 0.771 & 0.188 & 0.041 \\
\hline Employment & 0.050 & 0.943 & 0.007 \\
\hline Welfare receipt & 0.085 & 0.167 & 0.748 \\
\hline \multicolumn{4}{|c|}{ B. All immigrants } \\
\hline Inactivity & 0.733 & 0.186 & 0.082 \\
\hline Employment & 0.071 & 0.916 & 0.013 \\
\hline Welfare receipt & 0.084 & 0.149 & 0.768 \\
\hline \multicolumn{4}{|l|}{ C. EU citizens } \\
\hline Inactivity & 0.742 & 0.217 & 0.041 \\
\hline Employment & 0.053 & 0.937 & 0.010 \\
\hline Welfare receipt & 0.045 & 0.255 & 0.701 \\
\hline \multicolumn{4}{|c|}{ D. Non-EU citizens } \\
\hline Inactivity & 0.770 & 0.141 & 0.089 \\
\hline Employment & 0.098 & 0.882 & 0.020 \\
\hline Welfare receipt & 0.094 & 0.126 & 0.780 \\
\hline \multicolumn{4}{|c|}{ E. Immigrants with German citizenship } \\
\hline Inactivity & 0.681 & 0.222 & 0.096 \\
\hline Employment & 0.063 & 0.927 & 0.011 \\
\hline Welfare receipt & 0.083 & 0.140 & 0.777 \\
\hline
\end{tabular}

Note: Percentage of individuals weighted using cross-sectional weights. Source: SOEP 2005-2009.

alternative-specific coefficients. In addition, utility at time $t$ can vary with the previous labour market state, $\mathbf{y}_{i, t-1} \cdot \gamma_{j}$ is the corresponding coefficient vector that measures state dependence. We control for individual-specific unobserved heterogeneity by including the random error $\alpha_{i j}$, which relaxes the restrictive independence of irrelevant alternatives (IIA) assumption of the simple multinomial logit model, allowing for correlation in individual random effects $\alpha_{i j}$ across alternatives. ${ }^{8}$ Finally, $\epsilon_{i j t}$ denotes an independently distributed error term with a type I extreme value distribution.

We are interested in the conditional distribution of labour market states. For each period $t$, this distribution can be described by the conditional density $f_{t}\left(\mathbf{y}_{t} \mid \mathbf{x}_{t}, \mathbf{y}_{t-1}, \alpha ; \theta\right)$, where $\theta$ represents unknown parameters. Dynamic models of labour market state choice which allow for the presence of an unobserved effect raise the problem of endogenous initial conditions: whilst transitions within the panel of observations are modelled, the transition to the very first observed state has no observed predecessor. Because this initial state, $\mathbf{y}_{i 0}$, may be correlated with

\footnotetext{
${ }^{8}$ The IIA assumption implies that the probability ratio (or odds) of any two alternatives does not depend on available alternatives (see McFadden, 1974).
} 
the individual-specific unobserved heterogeneity, it is potentially endogenous (see Heckman, 1981b).

Two alternative solutions to the problem of endogenous initial conditions are applied in the literature. Some authors jointly model state transitions and the endogenous initial condition (Heckman, 1981b). We apply the second solution, namely the conditional maximum likelihood estimator suggested by Wooldridge (2005). Comparing the two approaches, several authors show that the Wooldridge estimator, which is more convenient, performs similar to the estimator proposed by Heckman (1981a,b). ${ }^{9}$

The starting point of the Wooldridge estimator is a density for the unobserved heterogeneity conditional on the explanatory variables and the initial state, $h\left(\alpha \mid \mathbf{x}, \mathbf{y}_{0} ; \delta\right)$, where $\delta$ represents the unknown parameters of this density. A convenient choice for this density is to assume that $\alpha_{i j} \sim N\left(\delta_{j 1}^{\prime} \mathbf{y}_{i 0}+\delta_{j 2}^{\prime} \mathbf{x}_{i}, \sigma_{a}^{2}\right)$. Although Wooldridge (2005) includes all time-varying variables of all time periods in the vector $\mathbf{x}_{i}$, many applications use individual-specific averages of a subset of the explanatory variables, which allows one to use unbalanced panel data. ${ }^{10} \mathrm{~A}$ consequence of this specification is that our model coincides with the Mundlak (1978) fixed effects approach. The Wooldridge approach thus models the unobserved heterogeneity $\alpha_{i j}$ as a function of the initial state $\mathbf{y}_{i 0}$, the set of averages of a subset of explanatory variables, $\mathbf{x}_{i}$, and a new random error, $a_{i j}$, that is uncorrelated with the initial state:

$$
\alpha_{i j}=\delta_{j 1}^{\prime} \mathbf{y}_{i 0}+\delta_{j 2}^{\prime} \mathbf{x}_{i}+a_{i j}
$$

We assume $a_{i j}$ to be normally distributed with zero mean and variance $\sigma_{a}^{2}$, that is, $a_{i j} \mid\left(\mathbf{y}_{i 0}, \mathbf{x}_{i}\right) \sim N\left(0, \sigma_{a}^{2}\right)$. Hence, the probability that individual $i$ is in state $j$ at time $t$ conditional on observed and unobserved characteristics and the labour market state in $t-1$ can be written as

$$
P\left(Y_{i t}=j \mid \mathbf{x}_{i}, \mathbf{y}_{i, t-1}, \mathbf{y}_{i 0}, \boldsymbol{a}_{i}\right)=\frac{\exp \left(\beta_{j}^{\prime} \mathbf{x}_{i t}+\gamma_{j}^{\prime} \mathbf{y}_{i, t-1}+\delta_{j 1}^{\prime} \mathbf{y}_{i 0}+\delta_{j 2}^{\prime} \mathbf{x}_{i}+a_{i j}\right)}{\sum_{k=1}^{J=3} \exp \left(\beta_{k}^{\prime} \mathbf{x}_{i t}+\gamma_{k}^{\prime} \mathbf{y}_{i, t-1}+\delta_{k 1}^{\prime} \mathbf{y}_{i 0}+\delta_{k 2}^{\prime} \mathbf{x}_{i}+a_{i k}\right)} .
$$

Normalizing the coefficient vectors $\beta_{1}, \gamma_{1}, \delta_{11}, \delta_{12}$, and the unobserved heterogeneity, $a_{i 1}$, to zero for the first alternative $(k=1)$, we can estimate a dynamic multinomial logit model with random effects. To obtain the unconditional

\footnotetext{
${ }^{9}$ For examples in the literature on welfare transitions applying the Heckman approach, see Hansen and Lofstrom (2009) or Hansen et al. (2006). The Wooldridge procedure has been applied to welfare and low-income transition problems by Cappellari and Jenkins (2009) or Hansen and Lofstrom (2011). For comparisons of the two approaches, see Arulampalam and Stewart (2009), Stewart (2007), Cappellari and Jenkins (2008), and Akay (2012).

${ }^{10}$ See, for example, Stewart (2007), Cappellari and Jenkins (2009), Prowse (2012). Akay (2012) shows that even in extremely unbalanced samples the Wooldridge estimator generates only small biases.
} 
likelihood function of our dynamic model, the random effect can be integrated out of the likelihood:

$$
L=\prod_{i=1}^{N} \int \prod_{t=1}^{T} f_{t}\left(\mathbf{y}_{i t} \mid \mathbf{x}_{i t}, \mathbf{y}_{i, t-1}, \alpha ; \theta\right) h\left(\alpha \mid \mathbf{x}_{i}, \mathbf{y}_{i 0} ; \delta\right) d \alpha .
$$

Since the integral has no analytical solution, we use Gauss-Hermite quadrature to integrate the random effect out of the corresponding log-likelihood and maximize the resulting marginal log-likelihood by the Newton-Raphson method. ${ }^{11}$ In principle, a native-immigrant difference in state dependence could be estimated based on a joint model for the different subsamples which considers a vector of interaction effects. However, this imposes homogeneous correlation patterns for the observable and unobservable factors in the model across subsamples. To ensure that our results are not affected or even generated by any such restrictions, we use the most flexible approach and present separate analyses for all subsamples.

To interpret our results, we predict probabilities $\bar{P}$ of transitions between labour market states for an individual randomly sampled from the population. The predicted probability of being in state $j$ at time $t$ given the state attained in $t-1$ can be obtained by integrating over the distribution of the random effect (see Skrondal and Rabe-Hesketh, 2009):

$$
\bar{P}\left(Y_{t}=j \mid \mathbf{y}_{t-1}, \mathbf{y}_{0}, \mathbf{x}^{0}\right)=\int \hat{P}\left(Y_{t}=j \mid \mathbf{y}_{t-1}, \mathbf{x}^{0}, \alpha\right) h\left(\alpha \mid \mathbf{x}, \mathbf{y}_{0} ; \delta\right) d \alpha,
$$

where we fix the vectors $\mathrm{y}_{0}$ and $\mathrm{x}^{0}$ at the sample averages. $\hat{P}$ is the conditional probability. Equation (5) is evaluated with respect to the nine possible labour market transitions. ${ }^{12}$ The uncertainty of the prediction can be assessed by approximate $95 \%$ confidence intervals. Using a parametric bootstrap approach, we simulate $\bar{P}\left(Y_{t}=j \mid \mathbf{y}_{t-1}, \mathbf{y}_{0}, \mathbf{x}^{0}\right)$ using 1,000 random draws from the sampling distribution of parameters and use the 25 th- and the 976 th-largest values.

\footnotetext{
${ }^{11}$ These procedures are available in the Stata programme -gllamm-, which is used for the estimation of the models presented in this article (see Skrondal and Rabe-Hesketh, 2003; Rabe-Hesketh et al., 2004). Maximum simulated likelihood (MSL) estimators could be used as an alternative method (e.g., Stewart, 2007).

${ }^{12}$ In nonlinear models the population-averaged probabilities which consider the entire distribution of the random effect are usually not identical to the conditional probabilities with a random effect of zero, that is, $\bar{P}\left(Y_{t}=j \mid \mathbf{y}_{t-1}, \mathbf{y}_{0}, \mathbf{x}^{0}\right) \neq \hat{P}\left(Y_{t}=j \mid \mathbf{y}_{t-1}, \mathbf{y}_{0}, \mathbf{x}^{0}, \alpha=0\right)$. Although the latter expression is computationally less demanding, Skrondal and Rabe-Hesketh (2009) recommend using population-averaged probabilities. Monte Carlo simulations show a considerably increased mean square error of prediction for conditional probabilities with $\alpha=0$. In addition, the interpretation of the two predictions differs. Whereas the population-averaged probability represents a prediction for an individual randomly sampled from the population, the conditional probability provides a prediction for a specific hypothetical individual.
} 


\section{Results}

\subsection{State dependence and labour market transitions}

In this subsection, we first take a detailed look at the evidence in favour of true state dependence. Then, we turn to the question to what extent immigrant-native differences in the dynamics of welfare receipt can be explained by differences in characteristics. The estimation results in Tables 3 and 4 indicate that past experience predicts current state choices. The highly significant coefficient estimates indicate that the log-odds of each state are higher when the individual was already in that state in the previous period. The predicted transition probabilities between period $t-1$ to $t$ in Table 5 provide more detailed insights. They reflect the expected behaviour of a randomly selected individual. ${ }^{13}$ Table 5 also provides simulated $95 \%$ confidence intervals of the transition rates. The results confirm that the probability of a current labour market state varies with the previous labour market state. This indicates the existence of true state dependence.

With respect to welfare entry, immigrants have on average a substantially higher propensity to move from inactivity to welfare than natives (3.8\% versus. $1.6 \%$, see Table 5). The difference in welfare entry rates may imply that immigrants are more likely to move from short-term unemployment to long-term unemployment, which tends to be accompanied by welfare benefits. Alternatively, earnings or unemployment insurance benefits are insufficient to provide the minimum income for immigrant households: immigrants have, on average, lower wages (see, e.g., Basilio and Bauer, 2010) and live in larger households. Thus, they receive lower unemployment benefits and have higher needs. Consequently, they are more likely to receive welfare in addition.

For all groups, the probability of exiting welfare for employment is higher than the probability of moving from inactivity to employment. This is consistent with the hypothesis that welfare recipients have stronger work incentives than inactive persons. However, immigrants are (insignificantly) less likely than natives to take up employment after welfare receipt.

Differences between the observed transition probabilities in Table 2 and their predicted values in Table 5 are indicative of the role played by individual-specific heterogeneity. After controlling for observed and unobserved heterogeneity, the persistence in welfare receipt reflected in Table 2 is reduced considerably from $75 \%$ and $77 \%$ to $3 \%$ and $9 \%$ for natives and immigrants, respectively (Table 5 , panels A and B). This suggests that the high persistence in welfare participation observed in the raw data can be attributed for the most part to observed and unobserved characteristics. In contrast, Hansen and Lofstrom (2009) found

\footnotetext{
${ }^{13}$ Predicted transition probabilities differ across individuals based on their characteristics. Therefore, we decided to calculate the probability for an 'average' person, which is a common approach when nonlinear functions are involved (Wooldridge, 2002). For comparison, we present the average of individually predicted transition rates in Table A6 in the online Appendix. The results are similar. Other authors also compare predicted transition rates with and without controls for unobserved heterogeneity. As this implies comparing consistent and inconsistent results, we do not apply this procedure.
} 


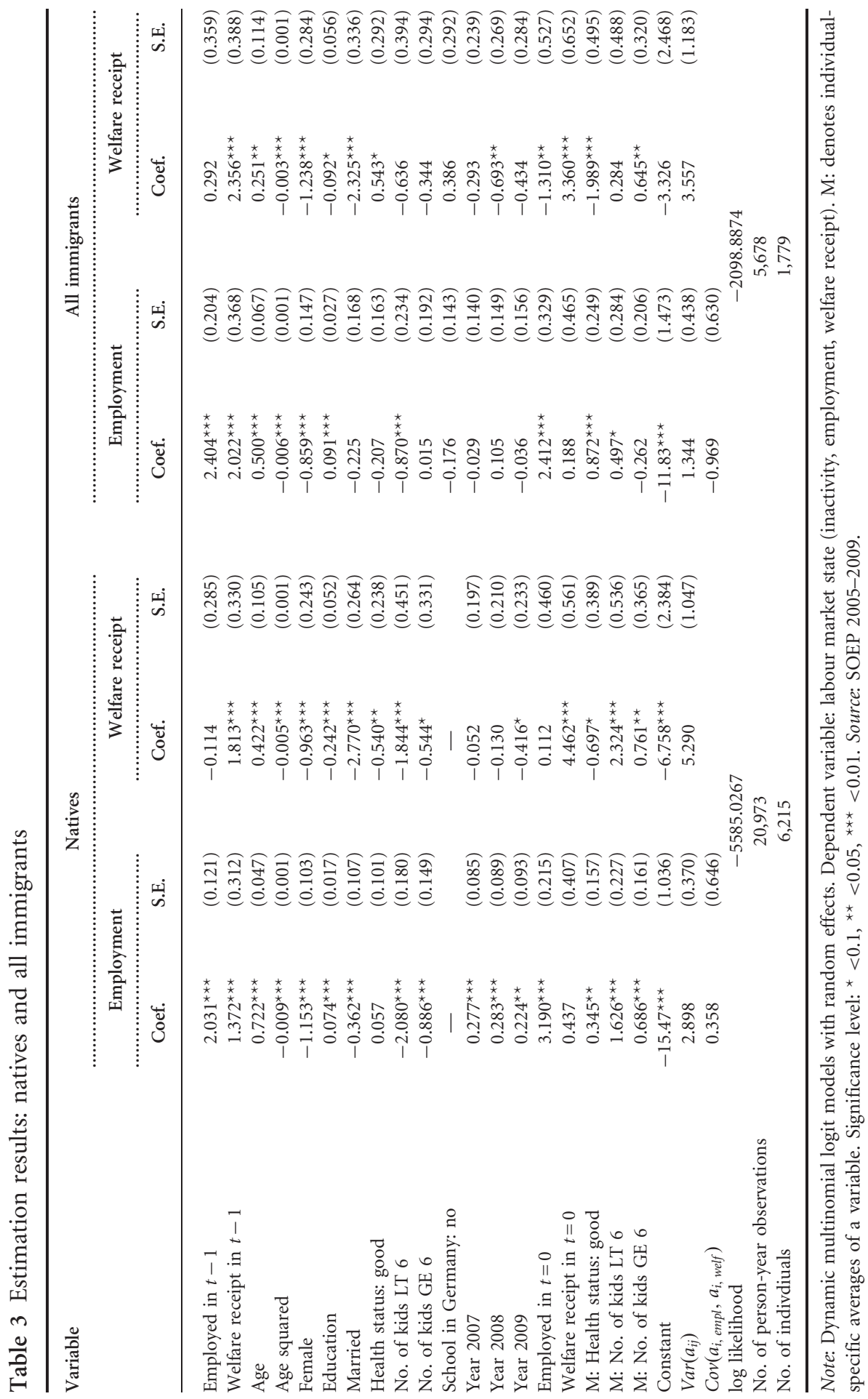




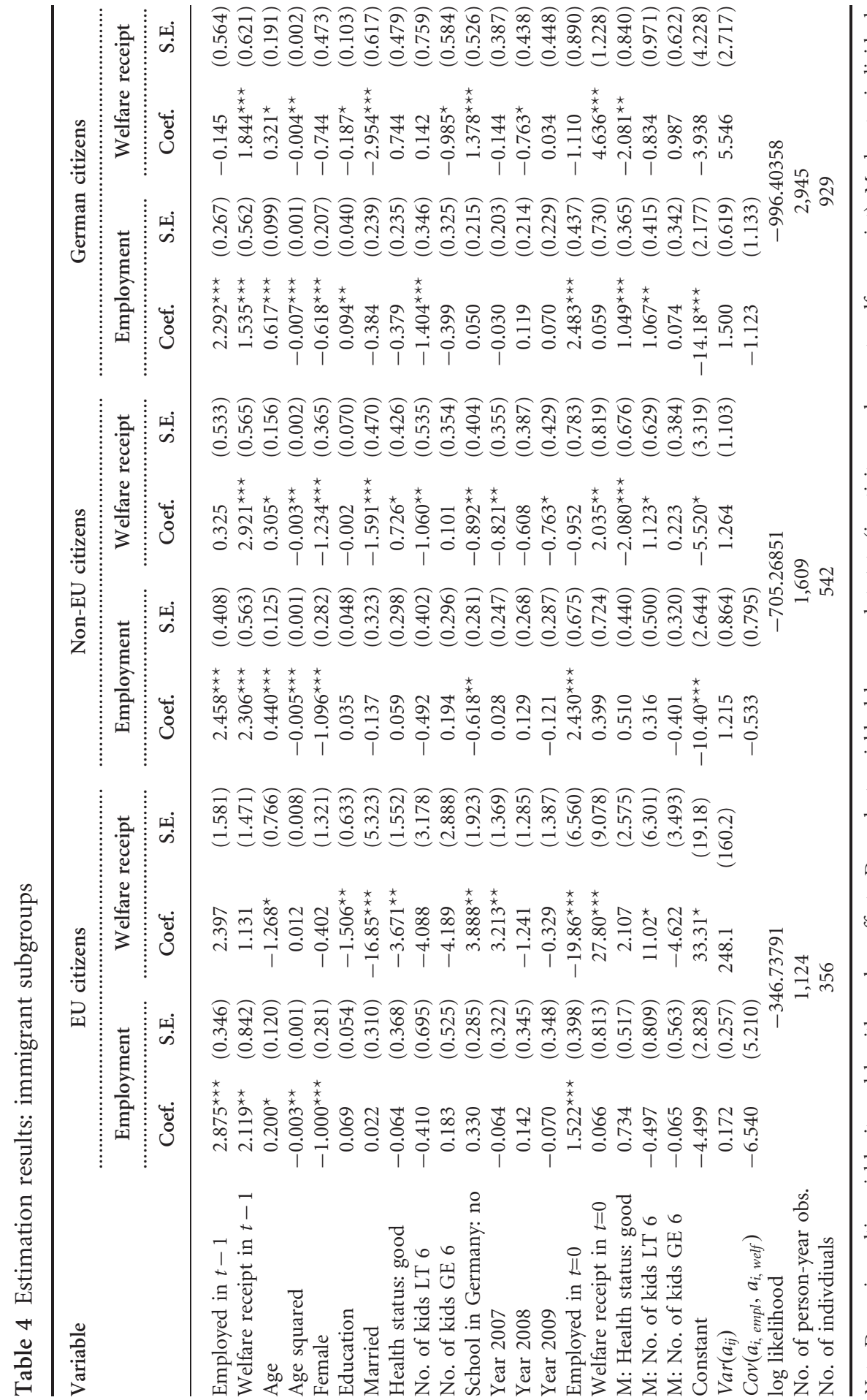


Table 5 Population-averaged probabilities of labour market transitions by immigrant group

\begin{tabular}{|c|c|c|c|c|c|c|c|c|c|}
\hline \multirow[t]{3}{*}{ State at time $t-1$} & \multicolumn{9}{|c|}{ State at time $t$} \\
\hline & \multicolumn{3}{|c|}{ Inactive } & \multicolumn{3}{|c|}{ Employment } & \multicolumn{3}{|c|}{ Welfare } \\
\hline & Mean & \multicolumn{2}{|c|}{ 95\%-CI } & Mean & \multicolumn{2}{|c|}{$95 \%-\mathrm{CI}$} & Mean & \multicolumn{2}{|c|}{ 95\%-CI } \\
\hline \multicolumn{10}{|l|}{ A. Natives } \\
\hline Inactivity & 0.264 & 0.232 & 0.302 & 0.720 & 0.681 & 0.753 & 0.016 & 0.011 & 0.026 \\
\hline Employment & 0.076 & 0.069 & 0.083 & 0.919 & 0.911 & 0.927 & 0.005 & 0.003 & 0.007 \\
\hline Welfare & 0.114 & 0.073 & 0.168 & 0.855 & 0.792 & 0.902 & 0.031 & 0.020 & 0.052 \\
\hline \multicolumn{10}{|l|}{ B. All immigrants } \\
\hline Inactivity & 0.446 & 0.368 & 0.531 & 0.516 & 0.428 & 0.586 & 0.038 & 0.026 & 0.073 \\
\hline Employment & 0.106 & 0.086 & 0.127 & 0.877 & 0.850 & 0.895 & 0.018 & 0.013 & 0.031 \\
\hline Welfare & 0.121 & 0.071 & 0.194 & 0.790 & 0.686 & 0.853 & 0.090 & 0.059 & 0.161 \\
\hline \multicolumn{10}{|l|}{ C. EU citizens } \\
\hline Inactivity & 0.493 & 0.361 & 0.636 & 0.499 & 0.357 & 0.634 & 0.008 & 0.001 & 0.010 \\
\hline Employment & 0.056 & 0.040 & 0.082 & 0.935 & 0.909 & 0.952 & 0.009 & 0.004 & 0.010 \\
\hline Welfare & 0.111 & 0.028 & 0.428 & 0.881 & 0.564 & 0.964 & 0.008 & 0.002 & 0.010 \\
\hline \multicolumn{10}{|l|}{ D. Non-EU citizens } \\
\hline Inactivity & 0.591 & 0.452 & 0.727 & 0.352 & 0.208 & 0.462 & 0.057 & 0.036 & 0.144 \\
\hline Employment & 0.180 & 0.120 & 0.252 & 0.791 & 0.706 & 0.849 & 0.030 & 0.018 & 0.083 \\
\hline Welfare & 0.140 & 0.060 & 0.263 & 0.647 & 0.408 & 0.781 & 0.213 & 0.109 & 0.442 \\
\hline \multicolumn{10}{|c|}{ E. Immigrants with German citizenship } \\
\hline Inactivity & 0.369 & 0.282 & 0.482 & 0.595 & 0.471 & 0.674 & 0.036 & 0.019 & 0.092 \\
\hline Employment & 0.086 & 0.067 & 0.110 & 0.901 & 0.870 & 0.921 & 0.012 & 0.007 & 0.032 \\
\hline Welfare & 0.136 & 0.064 & 0.269 & 0.798 & 0.603 & 0.882 & 0.066 & 0.034 & 0.196 \\
\hline
\end{tabular}

Note: Calculations are based on estimation results in Tables 3 and 4 . Simulation-based $95 \%$ confidence intervals are calculated using 1,000 replications.

welfare persistence of $66 \%$ for Swedish natives and $79 \%$ for refugee immigrants in the raw data. The predicted probabilities after accounting for unobserved heterogeneity and endogenous initial conditions yielded 10\% for natives and 63\% for refugee immigrants. The authors concluded that there was only spurious state dependence amongst natives and true state dependence amongst refugee immigrants. ${ }^{14}$

Furthermore, the results in Table 5 show considerable heterogeneity across immigrant subgroups: non-EU citizens exhibit by far the lowest employment stability and the highest risk of unemployment. They also have the highest persistence in welfare participation, the highest welfare entry, and the lowest welfare exit rates.

\footnotetext{
${ }^{14}$ Similarly, Biewen (2009) finds that of a raw poverty persistence rate of $61 \%$ about 31 percentage points remain as structural state dependence after controlling for observed and unobserved heterogeneity. Cappellari and Jenkins (2002) obtain a reduction of their aggregate state dependence rate from $52 \%$ in the raw data to $31 \%$ after controls. These levels of structural state dependence are much larger than ours, which suggests that the case of a welfare trap is rather weak.
} 
Based on the statistically significant coefficient estimates for the lagged state indicators, the predictions in Table 5 show that the probability of a transition to welfare in period $t$ is highest from the state of welfare receipt in period $t-1$. Both observations support the welfare trap hypothesis. On the other hand, the predicted probabilities of staying in welfare receipt are rather low. Furthermore, the probability of continuing welfare receipt is not significantly different from the probability of moving from inactivity to welfare: the confidence intervals overlap for all subsamples. Individuals who received welfare benefits in the past are not significantly more likely to participate in welfare in the future compared to individuals who were inactive. ${ }^{15}$ In conjunction with the work incentives of welfare recipients mentioned above, these results do not provide convincing evidence for the welfare trap hypothesis.

Next, we study whether immigrant-native differences in labour market transitions are connected to differences in characteristics. We calculate a transition matrix using immigrants' characteristics and natives' coefficients to simulate natives' transition probabilities if they had immigrants' characteristics. ${ }^{16}$ If the simulated probabilities for natives converge to those originally predicted for immigrants, then the immigrant-native gap can be attributed to differences in covariates. If, on the other hand, the immigrant-native gap persists, behavioural differences between immigrants and natives matter. The results (see Table 6) suggest that differences in transition probabilities diminish once differences in characteristics are taken into account. Natives would have a higher probability of welfare persistence if they had immigrants' characteristics: the originally predicted value of $3.1 \%$ (Table 5) increases to $4.6 \%$ and $4.5 \%$ (Table 6 ) assuming characteristics of EU citizens and of immigrants with German citizenship, respectively. Remarkably, natives would perform worse than EU citizens if they had their characteristics. ${ }^{17}$

However, with respect to non-EU citizens, substantial parts of the immigrantnative differences remain unexplained after accounting for differences in characteristics. Thus, group-specific labour market choices can only be partly explained by characteristics. If natives had the same characteristics as non-EU citizens, their welfare entry rates would be smaller, their welfare exit rates would be higher,

\footnotetext{
${ }^{15}$ We do not regard the transition from employment to welfare as an appropriate benchmark against which to compare the probability of welfare persistence since workers who become unemployed generally are entitled to unemployment insurance benefits (see Section 2). Hence, the difference between the probability of moving from employment to welfare and the probability of welfare persistence is supposed to arise from unemployment insurance regulations and is not induced by the welfare system.

${ }^{16}$ This provides reliable results to the extent that native behaviour remains constant if their distribution of observable characteristics shifts to immigrants' distribution, which we assume as a first approximation. Generally, it is important to point out that immigrants are not a random sample of their home country population. They are affected by their home countries' situations and host country immigration rules, both of which can vary over time.

${ }^{17}$ In general, we obtain similar simulation results using natives' characteristics and immigrants' coefficients. For details see Table A7 in the online Appendix.
} 
Table 6 Simulated population-averaged probabilities of labour market transitions for immigrants' characteristics and natives' coefficients

\begin{tabular}{|c|c|c|c|c|c|c|c|c|c|}
\hline \multirow[t]{3}{*}{ State at time $t-1$} & \multicolumn{9}{|c|}{ State at time $t$} \\
\hline & \multicolumn{3}{|c|}{ Inactive } & \multicolumn{3}{|c|}{ Employment } & \multicolumn{3}{|c|}{ Welfare } \\
\hline & Mean & $95 \%$ & $-\mathrm{CI}$ & Mean & 95 & -CI & Mean & 95 & $-\mathrm{CI}$ \\
\hline \multicolumn{10}{|c|}{ A. Characteristics of all immigrants } \\
\hline Inactivity & 0.338 & 0.306 & 0.382 & 0.635 & 0.591 & 0.666 & 0.027 & 0.019 & 0.039 \\
\hline Employment & 0.111 & 0.099 & 0.124 & 0.880 & .867 & 0.892 & 0.009 & 0.006 & 0.013 \\
\hline Welfare & 0.157 & 0.106 & 0.221 & 0.792 & 0.713 & 0.846 & 0.052 & 0.036 & 0.085 \\
\hline \multicolumn{10}{|c|}{ B. Characteristics of EU citizens } \\
\hline Inactivity & 0.308 & 0.272 & 0.344 & 0.668 & 0.631 & 0.703 & 0.024 & 0.017 & 0.036 \\
\hline Employment & 0.096 & 0.086 & 0.106 & 0.896 & .885 & 0.907 & 0.008 & 0.006 & 0.011 \\
\hline Welfare & 0.139 & 0.093 & 0.198 & 0.816 & 0.747 & 0.867 & 0.046 & 0.029 & 0.077 \\
\hline \multicolumn{10}{|c|}{ C. Characteristics of non-EU citizens } \\
\hline Inactivity & 0.403 & 0.365 & 0.442 & 0.562 & 0.524 & 0.597 & 0.035 & 0.026 & 0.052 \\
\hline Employment & 0.148 & 0.129 & 0.166 & 0.839 & 0.819 & 0.859 & 0.013 & 0.009 & 0.019 \\
\hline Welfare & 0.198 & 0.140 & 0.268 & 0.732 & 0.647 & 0.794 & 0.070 & 0.049 & 0.112 \\
\hline \multicolumn{10}{|c|}{ D. Characteristics of immigrants with German citizenship } \\
\hline Inactivity & 0.315 & 0.281 & 0.351 & 0.661 & 0.625 & 0.695 & 0.024 & 0.017 & 0.036 \\
\hline Employme & 0.099 & 0.089 & 0.110 & 0.893 & 0.882 & 0.904 & 0.008 & 0.006 & 0.011 \\
\hline Welfare & 0.143 & 0.098 & 0.203 & 0.812 & 0.738 & 0.864 & 0.045 & 0.030 & 0.075 \\
\hline
\end{tabular}

Note: Calculations are based on estimation results for natives in Table 3. Simulation-based $95 \%$ confidence intervals are calculated using 1,000 replications.

and their welfare persistence would increase to only $7 \%$ (Table 6, panel C) compared to the original value for non-EU citizens of $21.3 \%$ (Table 5, panel D).

\subsection{Unobserved heterogeneity and control variables}

The previous section showed that the observed persistence in welfare receipt is determined to a large extent by observed and unobserved individual-specific heterogeneity. Therefore, we now discuss the results for observables and for unobserved heterogeneity. Controlling for unobserved heterogeneity significantly improves the explanatory power of all models. The estimated variance of the random effect is larger for the transition to welfare receipt than for the transition to employment (see, e.g., the bottom rows of Table 3). This suggests that individual-specific unobserved heterogeneity plays a greater role in the transition to welfare receipt than in the transition to employment. The estimated covariances of the random effects are small and imprecise.

As part of the specification of the unobserved heterogeneity, $\alpha_{i j}$, our model incorporates individual-specific averages of a subset of variables (see variables labeled $\mathrm{M}$ in Tables 3 and 4). We focus on the health and number of children indicators because they may be endogenous to state transitions and it is thus important to account for their correlation with the unobserved heterogeneiy, 
$\alpha_{i j}$. Wald tests indicate the joint significance of the coefficients of the individualspecific averages. In addition, the estimations yield highly significant coefficient estimates for the initial conditions indicators, which suggests that the initial and the current labour market state are strongly correlated.

As control variables, our specification includes age as a measure of potential labour market experience, the number of years of education as an indicator of human capital, and the self-assessed health status to proxy health capital. In addition, the socio-economic background is controlled for using information on family status, gender, and the number of children below age six and aged six and older.

Generally, we obtain similar correlation patterns amongst natives and immigrants for most of the control variables (see Tables 3 and 4). Women and married individuals have lower odds of being employed or on welfare relative to inactivity than men and single persons. Higher education increases the probability ratio of employment to inactivity and makes welfare receipt less likely relative to inactivity. In the long run, the probability ratio of employment to inactivity decreases and that of welfare receipt increases with the number of children. Individuals with good health are more likely to be employed and less likely to receive welfare relative to inactivity. For natives, the year indicators reflect the positive aggregate labour market trend.

Since age enters the estimation equation as a second-order polynomial, we predicted transition probabilities over the life cycle for individuals with subsample-specific average characteristics. The age profiles of the transition rate from welfare are presented in Figs 1 and 2 for natives and immigrants. In general, the young have a high transition rate from welfare to employment; it increases until about age 40 and declines after age 50. In parallel, the probability of transiting from welfare receipt to inactivity decreases for the young and sharply increases for the old. Amongst immigrants, the probability of staying on welfare declines over the life cycle. For natives, the probability of staying on welfare hardly varies with age. The predicted probability of staying in welfare receipt for an immigrant with average characteristics is more than twice that of natives.

\subsection{Model extensions}

In this section, we analyse further heterogeneities in transition behaviour and report on robustness checks. A first model extension investigates whether the transition probabilities changed over time during our observation period. We estimated models in which the year indicators were interacted with lagged labour market states. For parsimony, the results are summarized graphically in Fig. A1 in the online Appendix. We find a decline in welfare persistence and an increase in welfare exit to employment over time. This may be a consequence of the welfare reform which encompassed a wide range of activation and training measures or of the positive development of the West German labour market.

The welfare reform took effect on 1 January 2005. Most survey interviews take place early in the year. It is possible that early in 2005 not all respondents were 


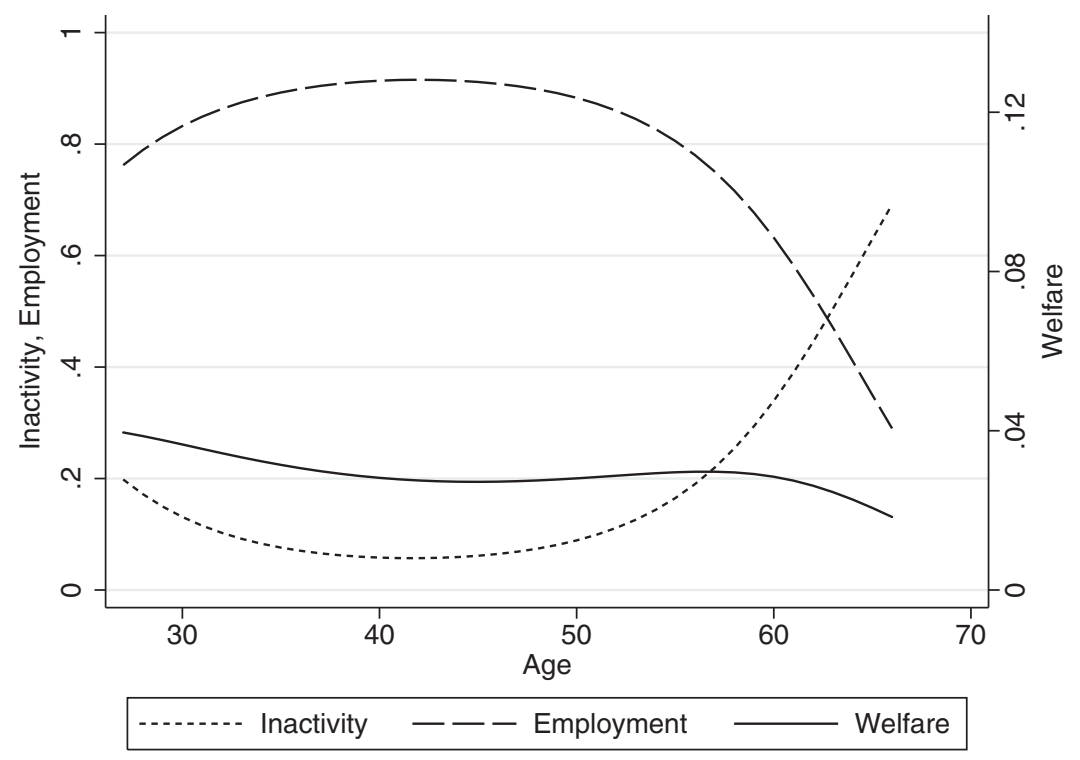

Fig. 1 Predicted probabilities of transitions from welfare receipt over the life span (natives).

Note: Calculations are based on the estimation results in Table 3. The probability of a persistence in welfare is denoted on right vertical axis.

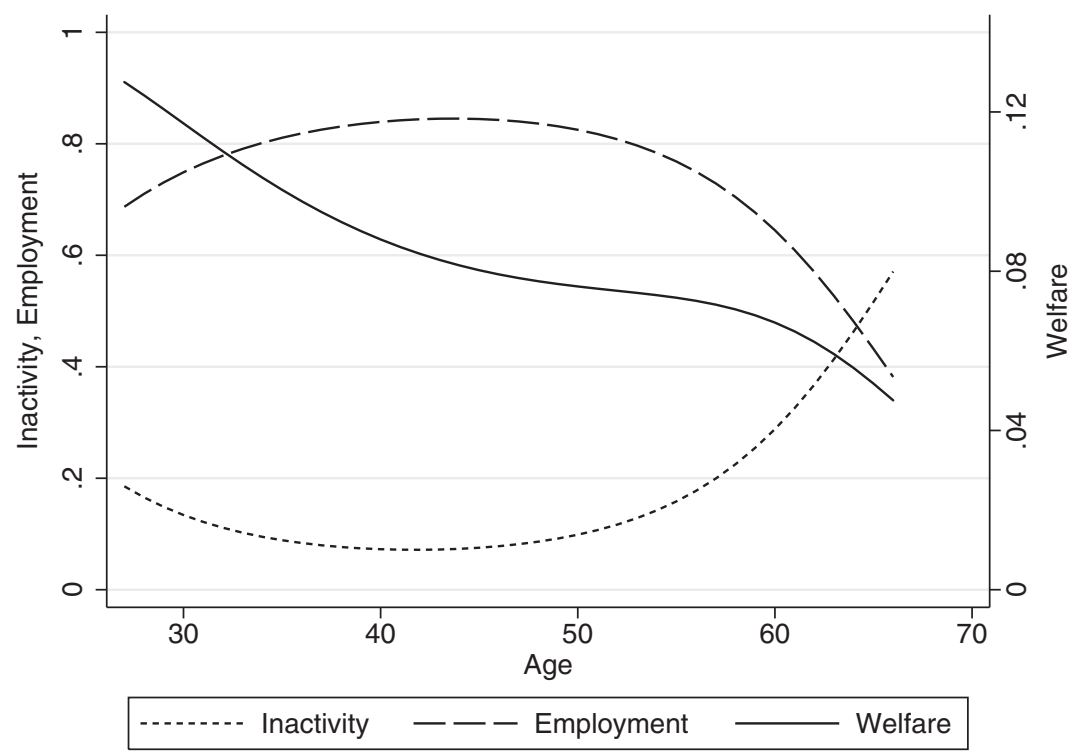

Fig. 2 Predicted probabilities of transitions from welfare receipt over the life span (all immigrants).

Note: Calculations are based on the estimation results in Table 3. The probability of a persistence in welfare is denoted on right vertical axis. 
aware of the institutional changes and thus did not provide correct information on their transfer. To test whether such potential coding problems affect our results, we repeated the estimations using 2006 instead of 2005 as initial condition. The estimation results are essentially identical to those presented. Therefore our results are robust to this potential coding problem. ${ }^{18}$

Similar to other household panel surveys, the SOEP data suffer from panel attrition. In principle, panel attrition may affect natives and immigrants differently as return migration affects only immigrants. To test whether potential non-random panel mortality affects the estimation results, we re-estimated our models adding a variable to the specification that indicates whether an individual leaves the sample in the period after the observed next transition. We obtained statistically insignificant coefficient estimates for these indicators, suggesting that panel attrition (including return migration) does not affect the results. Uhlendorff (2006) formally tests and rejects the correlation of panel attrition with labour market transitions in the SOEP. Based on these results, we conclude that panel attrition is unlikely to affect our results.

Finally, we address the sensitivity of our results to alternative categorizations of welfare recipients who are employed with earnings below households needs. In a first robustness check, we excluded these individuals from the estimation sample. In a second check, we coded them as employed individuals (instead of welfare recipients). ${ }^{19}$ Overall, the predicted transition patterns are consistent with those already reported, suggesting that our results are not sensitive to the categorization of these individuals. We also experimented with an even finer categorization in which we defined a separate category for employed welfare recipients. However, the model failed to converge for the immigrant sample, presumably due to the small number observations. ${ }^{20}$ When the model converged for the native sample, we find a large positive covariance between the random effects for employed and unemployed welfare recipients. This indicates a strong resemblance amongst individuals in these two states, after conditioning on the covariates.

\section{Conclusion}

We study the dynamics of welfare entry and exit in Germany and the relevance of true state dependence for natives and immigrants. We apply dynamic multinomial logit models, estimate transition probabilities between three labour market states, and determine the extent of true state dependence. The empirical method accounts for the endogeneity of the initial condition and for unobserved heterogeneity.

\footnotetext{
${ }^{18}$ For details see Tables A8 and A9 in the online Appendix.

${ }^{19}$ The predicted transition matrices are in Tables A10 and A11 in the online Appendix.

${ }^{20}$ For immigrants, only 89 person-year observations of the sample $(\mathrm{nT}=5,678)$ are categorized as employed welfare recipients. For natives, 166 person-year observations of the sample (nT=20,973) fall into this category.
} 
The results confirm that unobserved heterogeneity, the endogenous initial state, and correlations of unobservables with covariates affect transition patterns. Generally, the correlation of covariates with state transition patterns is similar for natives and immigrants. The probability of a transition to a given labour market state depends on the previous labour market state and differs between natives and immigrants.

Nevertheless, three findings challenge the hypothesis that the transfer system generates a general welfare trap: first, the predicted probability of welfare receipt in two successive periods at sample average characteristics is small once background characteristics are controlled for. This suggests that mostly these characteristics explain the high persistence in welfare observed in the raw data. Second, our model-based predictions show high rates of exit from welfare into employment for all groups. In particular, the probability of moving from welfare to employment is significantly higher than the probability of moving from inactivity to employment. Thus, welfare recipients appear to have stronger work incentives than inactive persons. Such work incentives may emerge, for example, from tight budget constraints or active labour market and job creation programmes (e.g., Hohmeyer and Wolff, 2010). Third, the probability of moving from inactivity to welfare is not significantly different from the probability of staying in the state of welfare participation. In sum, we interpret these results as evidence against a general welfare trap in the German welfare programme.

The relatively low relevance of structural state dependence found in our study may be explained by a number of features of the German welfare system: (i) the philosophy of the post-reform welfare state is explicitly 'to assist and demand', that is, claimants are required to actively search for work; also, (ii) claimants face substantial sanctions if they do not respond. Both factors should increase transitions out of welfare and out of unemployment. (iii) The post-reform system offers enhanced work incentives; for example, the marginal tax rates for single individuals are below 100\% up to earnings of 1200 euros per month. (iv) Possibly the labour market does not discriminate against prior welfare recipients, allowing them to work their way out of welfare. (v) The increasing labour force participation rate of women may render households more flexible in generating earnings and preventing welfare persistence.

Interestingly, our finding of no significant welfare trap differs both from Hansen and Lofstrom (2009) and from Bratsberg et al. (2010), who find a substantial welfare trap for refugees in Sweden and immigrant-native differences in non-employment persistence in Norway, respectively. The authors point to institutional details that are potentially relevant here: in both Scandinavian countries immigrants are treated exactly like natives. However, in Sweden the marginal reduction rate of welfare benefits with increasing family income amounts to $100 \%$. In Norway, the effective replacement rate for low wage earners with many children in the disability system can exceed $100 \%$. These characteristics imply low work incentives which may generate persistence in transfer receipt. As the German welfare system clearly differs in this respect, work incentives may explain the different welfare trap results. 
The analysis identified non-EU citizens, who are mostly of Turkish origin or citizens of the successor states of former Yugoslavia, as those with the least stable employment, the highest persistence in welfare participation, the highest welfare entry, and the lowest welfare exit rates. Our simulation exercise suggests that a large part of the immigrant-native difference in labour market transitions can be explained by socioeconomic characteristics. However, we find a substantial unexplained part of the immigrant-native gap in welfare persistence for non-EU citizens.

The problematic situation of non-EU citizens might be explained by several factors: first, because these individuals are employed frequently in industries that are particularly vulnerable to economic downturns (see Kogan, 2004), economic fluctuations may exert a particularly destabilizing effect on their employment situation. $^{21}$ Second, discrimination and exclusion from employment as civil servants could present obstacles to employment (e.g., Kogan, 2007). Third, Uhlendorff and Zimmermann (2006) report that unemployed immigrants, in particular those from Turkey, experience a longer duration of unemployment because they need more time to find a job. Fourth, higher unemployment amongst immigrants may be attributed to immigrant-native differences in risk attitudes. In a recent study on second-generation immigrants in Germany, Constant et al. (2011) report low risk aversion of immigrants that may result, for example, in high reservation wages. Fifth, the group of non-EU citizens may combine those least willing to integrate into the host country society as better integrated immigrants may already have opted for German citizenship. Finally, Bratsberg et al. (2010) report that the replacement ratio of public transfers with respect to own income in Norway differs substantially depending on human capital and the number of dependent children. These patterns also exist in Germany and generate substantial disincentives to take up employment for those with many children and low human capital, a characteristic of many immigrant households.

Our analysis leads us to the following policy recommendations. First, the regulations of the welfare system should take into account that natives and immigrants, particularly non-EU citizens, have different probabilities of labour market transitions. On the one hand, the higher propensity of immigrants for continued welfare receipt could be due to their preferences. In this case, more selective immigration requirements or specific eligibility rules may be advisable. On the other hand, the immigrant-native differences in the dynamics of welfare receipt may be due to different constraints. For example, current regulations for the recognition of foreign degrees in Germany lack transparency because there is no nationwide system, and responsibility lies with federal states. Therefore, we recommend common standards and transparency for the recognition of foreign qualifications to support the employability of non-EU citizens and to reduce potential labour market discrimination. Second, as background characteristics are important in explaining welfare persistence, an improvement of the relevant characteristics, for

${ }^{21}$ This is what Bratsberg et al. (2010) confirm for the case of Norwegian immigrants. 
example raising human capital through training and education, could support exit from welfare receipt.

Finally, our analysis does not indicate a general failure of the welfare system in the sense that it creates a welfare trap. The immigrant-native gap in welfare participation is mostly connected to characteristics. Overall, work incentives appear to reach welfare recipients. Given the rising share of individuals with a migration background in the population and considering the demographic changes ahead, aging societies, such as the German one, cannot afford to underuse the potential of their workforces. Therefore, the primary policy goal should be to foster employment continuity, particularly amongst non-EU citizens.

\section{Supplementary material}

Supplementary material is available online at www.oep.oxfordjournals.org.

\section{Acknowledgements}

We thank three anonymous referees, Lorenzo Cappellari, Xiaodong Gong, Sebastian Königs, Alexander Mosthaf, Stephan Whelan, the participants of the CESifo area conference 'Employment and Social Protection', the DIW Applied Micro seminar, the Laboreconometrics 2011 Sydney meeting, and the SOFI seminar for helpful comments.

\section{References}

Akay, A. (2012) Finite-sample comparison of alternative methods for estimating dynamic panel data models, Journal of Applied Econometrics, 27, 1189-204.

Aldashev, A. and Fitzenberger, B. (2009) Der Zugang von Arbeitnehmern in den Bezug von Arbeitslosengeld II, Discussion Paper No. 09-063, Zentrum für Europäische Wirtschaftsforschung/Center for European Economic Research, Mannheim.

Arulampalam, W. and Stewart, M.B. (2009) Simplified implementation of the Heckman estimator of the dynamic probit model and a comparison with alternative estimators, Oxford Bulletin of Economics and Statistics, 71, 659-81.

Barrett, A. and McCarthy, Y. (2008) Immigrants and welfare programmes: exploring the interactions between immigrant characteristics, immigrant welfare dependence, and welfare policy, Oxford Review of Economic Policy, 24, 543-60.

Basilio, L. and Bauer, T. (2010) Transferability of human capital and immigrant assimilation: an analysis for Germany, Discussion Paper No. 4716, Institute for the Study of Labor (IZA), Bonn.

Biewen, M. (2009) Measuring state dependence in individual poverty histories when there is feedback to employment status and household composition, Journal of Applied Econometrics, 24, 1095-116.

Blank, R.M. and Ruggles, P. (1994) Short-term recidivism among public-assistance recipients, American Economic Review, 84, 49-53.

BMAS (Bundesministerium für Arbeit und Soziales) (ed.) (2010) Übersicht über das Sozialrecht, BW Bildung und Wissen, Nürnberg. 
Borjas, G.J. (1999) Immigration and welfare magnets, Journal of Labor Economics, 17, 607-37.

Bratsberg, B., Raaum, O., and Røed, K. (2010) When minority labor migrants meet the welfare state, Journal of Labor Economics, 28, 633-76.

Bruckmeier, K. and Wiemers, J. (2012) A new targeting: a new take-up? Non-take-up of social assistance in Germany after social policy reforms, Empirical Economics, 43, 565-80.

Caliendo, M. (2009) Income support systems, labor market policies and labor supply: the German experience, Discussion Paper No. 4665, Institute for the Study of Labor (IZA), Bonn.

Cappellari, L. and Jenkins, S.P. (2002) Who stays poor? Who becomes poor? Evidence from the British Household Panel Survey, Economic Journal, 112, C60-7.

Cappellari, L. and Jenkins, S.P. (2004) Modelling low pay transition probabilities, accounting for panel attrition, non-response, and initial conditions, Discussion Paper No. 1232, CESifo Group, Munich.

Cappellari, L. and Jenkins, S.P. (2008) The dynamics of social assistance receipt: measurement and modelling issues, with an application to Britain, Discussion Paper No. 67, OECD, Directorate for Employment, Labour and Social Affairs, Paris.

Cappellari, L. and Jenkins, S.P. (2009) The dynamics of social assistance benefit receipt in Britain, Discussion Paper No. 4457, Institute for the Study of Labor (IZA).

Chay, K.Y., Hoynes, H.W., and Hyslop, D. (2004) True state dependence in monthly welfare participation: a nonexperimental analysis, Discussion Paper No. 05-33, Department of Economics, University of California at Davis.

Classen, G. (2009) Leistungen für Ausländer nach SGB II, SGB XII und AsylbLG, available at http://www.fluechtlingsinfo-berlin.de/fr/pdf/Eckpunkte_SGB_II_XII_Auslaender.pdf (accessed 12 November 2010).

Constant, A.F., Krause, A., Rinne, U., and Zimmermann, K.F. (2011) Economic preferences and attitudes of the unemployed: are natives and second generation migrants alike? International Journal of Manpower, 32, 825-51.

Devicienti, F. (2011) Estimating poverty persistence in Britain, Empirical Economics, 40, 657-86.

Farrell, L. and Frijters, P. (2008) Choosing to become a 'lost cause': the perverse effects of benefit preconditions, Oxford Economic Papers, 60, 1-19.

Green, D.A. and Warburton, W.P. (2004) Tightening a welfare system: the effects of benefit denial on future welfare receipt, Journal of Public Economics, 88, 1471-93.

Hansen, J. and Lofstrom, M. (2009) The dynamics of immigrant welfare and labor market behavior, Journal of Population Economics, 22, 941-70.

Hansen, J. and Lofstrom, M. (2011) Immigrant-native differences in welfare participation: the role of entry and exit rates, Industrial Relations: A Journal of Economy and Society, 50, 412-42.

Hansen, J., Lofstrom, M., and Zhang, X. (2006) State dependence in Canadian welfare participation, Discussion Paper No. 2266, Institute for the Study of Labor (IZA), Bonn.

Heckman, J.J. (1981a) Heterogeneity and state dependence, in S. Rosen (ed.) Studies in Labor Markets, University of Chicago Press, Chicago, IL. 
Heckman, J.J. (1981b) The incidental parameters problem and the problem of initial conditions in estimating a discrete time-discrete data stochastic process, in C.F. Manski and D. McFadden (eds) Structural Analysis of Discrete Data with Econometric Applications, MIT Press, Cambridge, MA.

Hohmeyer, K. and Wolff, J. (2010) Direct job creation in Germany revisited. Is it effective for welfare recipients and does it matter whether participants receive a wage? Discussion Paper No. 21, Institute for Employment Research (IAB), Nuremberg.

Kaestner, R. and Kaushal, N. (2005) Immigrant and native responses to welfare reform, Journal of Population Economics, 18, 69-92.

Kogan, I. (2004) Last hired, first fired? The unemployment dynamics of male immigrants in Germany, European Sociological Review, 20, 445-61.

Kogan, I. (2007) Continuing ethnic segmentation in Austria, in A.F. Heath and S.Y. Cheung (eds) Unequal Chances: Ethnic Minorities in Western Labour Markets, Oxford University Press, Oxford.

McFadden, D. (1974) Conditional logit analysis of qualitative choice behavior, in P. Zarembka (ed.) Frontiers in Econometrics, Academic Press, New York.

Moffitt, R. (1992) Incentive effects of the U.S. welfare system: a review, Journal of Economic Literature, 30, 1-61.

Mundlak, Y. (1978) On the pooling of time series and cross section data, Econometrica, 46, 69-85.

Plant, M.W. (1984) An empirical analysis of welfare dependence, American Economic Review, 74, 673-84.

Prowse, V. (2012) Modeling employment dynamics with state dependence and unobserved heterogeneity, Journal of Business \& Economic Statistics, 30, 411-31.

Rabe-Hesketh, S., Skrondal, A., and Pickles, A. (2004) Gllamm manual, Discussion Paper No. 1160, U.C. Berkeley Division of Biostatistics, Berkeley Electronic Press, Berkeley, CA.

Riphahn, R.T. (2001) Rational poverty or poor rationality? The take-up study of social assistance benefits, Review of Income and Wealth, 47, 379-98.

Riphahn, R.T. (2004) Immigrant participation in social assistance programs: evidence from German guestworkers, Applied Economics Quarterly, 50, 329-62.

Riphahn, R.T. and Wunder, C. (2012) Patterns of welfare dependence before and after a reform: evidence from first generation immigrants and natives in Germany, Review of Income and Wealth, Early View, doi: 10.1111/j.1475-4991.2012.00518.x.

Sandefur, G. and Cook, S. (1997) Duration of public assistance receipt: is welfare a trap? Discussion Papers No. 1129-97, Institute for Research on Poverty, University of Wisconsin, Madison, WI.

Schels, B. (2011) Young beneficiaries' routes off benefits through labour market integration: the case of Germany, Zeitschrift für ArbeitsmarktForschung/Journal for Labour Market Research, 44, 261-78.

Skrondal, A. and Rabe-Hesketh, S. (2003) Multilevel logistic regression for polytomous data and rankings, Psychometrika, 68, 267-87.

Skrondal, A. and Rabe-Hesketh, S. (2009) Prediction in multilevel generalized linear models, Journal Of the Royal Statistical Society Series A, 172, 659-87.

Stewart, M.B. (2007) The interrelated dynamics of unemployment and low-wage employment, Journal of Applied Econometrics, 22, 511-31. 
Uhlendorff, A. (2006) From no pay to low pay and back again? A multi-state model of low pay dynamics, Discussion Paper No. 2482, Institute for the Study of Labor (IZA), Bonn.

Uhlendorff, A. and Zimmermann, K.F. (2006) Unemployment dynamics among migrants and natives, Discussion Paper No. 2299, Institute for the Study of Labor (IZA), Bonn.

Wagner, G.G., Frick, J.R., and Schupp, J. (2007) The German Socio-Economic Panel Study (SOEP)—scope, evolution and enhancemants, Schmollers Jahrbuch (Journal of Applied Social Science Studies), 127, 139-69.

Wilde, J. (2003) Was reizt Sozialhilfeempfänger zum Ausstieg? Eine empirische Untersuchung mit dem Niedrigeinkommens-Panel, Journal of Economics and Statistics (Jahrbcher fr Nationaloekonomie und Statistik), 223, 719-42.

Wilde, J. and Kubis, A. (2005) Nichtinanspruchnahme von Sozialhilfe. Eine empirische Analyse des Unerwarteten, Journal of Economics and Statistics (Jahrbücher für Nationaloekonomie und Statistik), 225, 347-73.

Wooldridge, J.M. (2002) Econometric Analysis of Cross Section and Panel Data, MIT Press, Cambridge, MA.

Wooldridge, J.M. (2005) Simple solutions to the initial conditions problem in dynamic, nonlinear panel data models with unobserved heterogeneity, Journal of Applied Econometrics, 20, 39-54. 